\title{
Urgensi Pencegahan dan Pengendalian Risiko Infeksi Leishmaniasis atas Kontingen Garuda di Lebanon
}

\author{
I Dewa Ketut Kerta Widana ${ }^{1 *}$, Abimanyu Hilmawan ${ }^{1}$ \\ ${ }^{1}$ Universitas Pertahanan, Kompleks IPSC Sentul, Bogor \\ * Corresponding Author: dkwidana@gmail.com \\ Info Artikel : Diterima Februari 2019 ; Disetujui Maret 2019 ; Publikasi April 2019
}

\begin{abstract}
ABSTRAK
Latar belakang: Suriah merupakan wilayah endemik Cutaneous Leishmaniasis dengan kasus infeksi yang terburuk di dunia. Akibat perang saudara dan terorisme, infeksi penyakit Cutaneous Leishmaniasis atas rakyat Suriah menjadi tidak terkendali dengan kasus sebesar 58.156 di tahun 2011, 71.996 di tahun 2013, dan 50.972 kasus di tahun 2015. Konflik berkepanjangan mendorong dislokasi rakyat Suriah ke negara-negara di sekitarnya, salah satunya Lebanon. Catatan kasus Cutaneous Leishmaniasis di Lebanon selalu baik dalam jangka tahun 2006 hingga 2015 (selalu di bawah 7 kasus). Namun akibat dislokasi rakyat Suriah ke Lebanon, menimbulkan peningkatan imported case Cutaneous Leishmaniasis yang terus meningkat dari 1.033 kasus di tahun 2013 menjadi 1.393 di tahun 2015. Sejak tahun 2006, Indonesia mengirim Kontingen Garuda untuk misi perdamaian di perbatasan Lebanon-Israel. Dengan meningkatnya risiko infeksi Cutaneous Leishmaniasis di Lebanon, belum adanya gambaran berapa lama konflik di Suriah akan berakhir, dan belum jelasnya kapan misi perdamaian Indonesia di Lebanon akan selesai, risiko infeksi Leishmaniasis atas prajurit TNI semakin tinggi. Tujuan paper ini adalah memberikan masukan bagaimana Kontingen Garuda di Lebanon memperkecil risiko infeksi Cutaneous Leishmaniasis.

Metode: Paper ini disusun dengan teknik studi literatur (literature review) mengenai praktik pencegahan dan pengendalian infeksi Leishmaniasis menggunakan teknik Miles, Huberman dan Saldana (2014) yaitu data condensation, data display, dan conclusion drawing.

Hasil: Vaksin penyakit Leishmaniasis belum ditemukan dan obat-obatan untuk penyembuhannya yang tersedia saat ini masih memiliki toksisitas tinggi. Mencegah gigitan lalat pasir dengan alat pelindung diri, rekayasa lingkungan untuk penurunan populasi lalat pasir dan hewan inang, serta mengkarantina dan memulihkan inang manusia adalah cara paling efektif untuk mengontrol risiko infeksi Leishmaniasis.

Simpulan: Mencegah gigitan lalat pasir adalah cara terbaik dalam memperkecil risiko infeksi Leishmaniasis. Pemberantasan vektor dan inang, serta penggunaan alat pelindung diri adalah langkah yang perlu diambil Kontingen Garuda untuk memperkecil risiko infeksi Leishmaniasis.
\end{abstract}

Kata kunci: Cutaneous Leishmaniasis; Kontingen Garuda; Lebanon; pencegahan; pengendalian

\section{ABSTRACT}

Title: The Urgency to Prevent and Control the Risk of Leishmaniasis Infection on the Garuda Contingent in Lebanon

Background: Syria is an endemic region of Cutaneous Leishmaniasis with the worst infection case in the world. Fueled by civil war and terrorism, Cutaneous Leishmaniasis infection ravage the country with 58.156 cases in 2011, 71.996 cases in 2013, and 50.972 cases in 2015. The prolonged conflict force the dislocations of Syrians to neighbouring countries such as Lebanon. Cutaneous Leishmaniasis case in Lebanon is relatively low but as the refugee from Syria entering the border, the imported case of Cutaneous Leishmaniasis increases. As Indonesia keep sending Garuda Contingent to Lebanon for peacekeeping mission since 2006, this caused a worry that the troops may infected with Leishmaniasis. The aim of this paper is to give inputs about how to suppress the risk of infection between Garuda Contingent in Lebanon. 
Methods: literature review from journals about Leishmaniasis prevention and control using Miles, Huberman, and Saldana's (2014) analytical technique of data condensation, data display, and conclusion drawing.

Results: Vaccine for Leishmaniasis is yet to be found and the medicines for the treatment is still have high toxicity. Preventing the sandfly bites by using self protective measures/equipment, environmental engineering to reduce Leishmaniasis reservoir and vector, quarantine the infected human and curing the victim are the most effective way to control the risk of Leishmaniasis infeections.

Conclusion: Preventing sandfly bite is the best way to suppress the risk of Leishmaniasis infection. Vector and reservoir control, and the use self protective measures and equipment is necessary to lower the Leishmaniasis infection risks to Garuda Contingent.

Keywords: Cutaneous Leishmaniasis; Garuda Contingent; Lebanon; prevention; control.

\section{PENDAHULUAN}

Leishmaniasis adalah penyakit infeksi akibat parasit protozoa intraselular dari genus Leishmania yang disebarkan oleh gigitan vektor lalat pasir (sandfly) betina. Secara umum Leishmaniasis memiliki 4 gejala klinis, Visceral Leishmaniasis (VL) yang menimbulkan pembengkakan organ dalam, Post-KalaAzar-Dermal Leishmaniasis (PKDL) yaitu komplikasi yang muncul setelah seseorang sembuh dari VL, Cutaneous Leishmaniasis (CL) yang menimbulkan borok (lesion) di kulit, dan Mucocutaneus Leishmaniasis (ML) yang merusak jaringan mukosal. VL merupakan bentuk infeksi Leishmaniasis yang terparah karena dapat menimbulkan pembengkakan organ dalam (hati dan limpa) dan pelemahan daya tahan tubuh, sedangkan CL merupakan kasus yang lebih sering terjadi di dunia. Penyakit ini tersebar di wilayah tropis dan sub-tropis dan terkategori neglected tropical disease oleh PBB dengan wilayah penyebaran utama di sub-kontinen India, basin Mediterania (Timur Tengah, Eropa Selatan, dan Afrika Utara), dan Amerika Selatan. Per tahun, diperkirakan terdapat 2.000.000 kasus infeksi Leishmaniasis (500.000 VL dan 1.500.000 CL) di seluruh dunia. Leishmaniasis juga diperkirakan menimbulkan korban kematian sebanyak 50.000 jiwa per tahun, menjadikannya penyakit infeksi akibat parasit penyebab kematian kedua terbesar setelah malaria. ${ }^{1}$

Suriah merupakan wilayah endemik CL dan dinyatakan PBB sebagai negara berstatus high burden. ${ }^{2}$ Sejak tahun 2006, kasus infeksi CL di Suriah sudah sangat tinggi, yaitu 18.732 kasus dan terus meningkat menjadi 29.104 kasus di tahun 2008. ${ }^{2}$ Kasus infeksi CL di Suriah terus memburuk dengan puncaknya di tahun 2013. Memburuknya infeksi Leishmaniasis di Suriah adalah akibat perang saudara dan munculnya kelompok teroris (Daesh/ISIS) yang menimbulkan rusaknya infrastruktur dasar dan hilangnya sistem pelayanan kesehatan. ${ }^{3}$ Perang saudara dan terorisme juga menimbulkan dislokasi penduduk Suriah ke negaranegara sekitarnya seperti Turki, Lebanon, dan Yordania dan menimbulkan krisis pengungsi. Terdapat hubungan kuat antara keberadaan kamp pengungsi Suriah dengan munculnya kasus luar biasa CL di negara-negara tersebut serta masuknya spesies parasit Leishmania baru ke wilayah yang sebelumnya nonendemik. $^{3}$
Lebanon adalah salah satu negara yang menjadi sasaran para pengungsi asal Suriah. Lebanon merupakan wilayah endemik CL dan VL, namun program pengendalian yang dilakukan pemerintah berhasil menekan angka infeksinya di Lebanon. Dari tahun 2006 hingga 2013, total kasus CL di Lebanon hanya 14 kasus. Namun setelah pengungsi asal Suriah masuk, tercatat terdapat 1.033 imported case CL di Lebanon di tahun 2013. Di tahun 2015, imported case CL meningkat menjadi 1.393 kasus, menunjukkan kenaikan sebesar lebih dari 30\%. Lebanon merupakan salah satu negara dengan wilayah tersempit di Timur Tengah, namun jumlah pengungsi Suriah yang ditampungnya sangat besar, yaitu 948,849 orang per 31 Desember 2018, ${ }^{4}$ membuatnya sebagai salah satu negara dengan pengungsi terpadat di Timur Tengah. Ditambah perubahan iklim, belum selesainya konflik antara Lebanon-Israel, dan stagnasi ekonomi ${ }^{5}$ menunjukkan tingginya risiko epidemik CL di Lebanon. Pengungsi asal Suriah yang terjangkit CL di Lebanon berperan sebagai inang/reservoir, sedangkan perubahan iklim dapat membuat meningkatnya populasi lalat pasir dan wilayah persebarannya. ${ }^{6}$ Konflik Israel-Lebanon yang dapat kembali pecah kapan saja, dan stagnasi ekonomi Lebanon dapat membuat rusaknya infrastruktur yang berdampak pada menurunnya layanan kesehatan dan kesejahteraan masyarakat Lebanon. Upaya pemerintah Lebanon melakukan pengendalian inang dan vektor Leishmaniasis juga akan terganggunya seperti halnya yang terjadi di Suriah.

Sejak tahun 2006, Indonesia mengirim pasukan perdamaian Kontingen Garuda ke Lebanon untuk misi perdamaian mengawasi gencatan senjata antara Lebanon-Israel. Setiap tahun Indonesia secara rutin mengirimkan 1.200 personil dengan durasi operasi selama 1 tahun. Munculnya kasus luar biasa CL akibat kedatangan pengungsi asal Suriah ${ }^{7}$ menggambarkan adanya peningkatan risiko infeksi Leishmaniasis atas prajurit Kontingen Garuda dibandingkan tahun-tahun sebelumnya. Prajurit yang terinfeksi CL dapat menurunkan performa pelaksanaan misi termasuk mengganggu karirnya di militer karena pengobatannya memakan waktu, dan lesi yang ditimbulkan dapat merusak penampilan (terutama jika di wajah). Bahkan jika yang menginfeksi adalah spesies parasit Leishmania Tropica (yang umumnya menimbulkan CL 
di Suriah) prajurit yang terinfeksi berisiko mengalami VL. ${ }^{8}$ Perlu diketahui bahwa dari total 2.420 keluarga pengungsi Suriah yang didiagnosa terinfeksi CL di Lebanon (tahun 2017), 2.057 (85\%)-nya terinfeksi spesies parasit Leishamania Tropica dan sisanya oleh Leishmania Major. ${ }^{9}$ Artinya risiko infeksi Leishmaniasis oleh parasit Leishmania Tropica cukup tinggi di Lebanon, dan ini menandakan prajurit yang terinfeksi juga berpotensi mengalami VL. Tujuan penulisan paper ini adalah memberikan analisis bagaimana memberikan perlindungan yang efektif atas Kontingen Garuda di Lebanon dari ancaman infeksi Leishmaniasis.

\section{MATERI DAN METODE}

Jenis paper ini adalah deskriptif, untuk mengetahui dan menjelaskan fenomena peningkatan imported case Cutaneous Leishmaniasis di Lebanon akibat perang saudara di Suriah, pengaruhnya terhadap risiko infeksi Leishmaniasis atas Kontingen Garuda di Lebanon, dan bagaimana program pencegahan dan pengendalian yang harus dilakukan. Dalam penelitian ini, pengambilan data primer dilakukan di Kantor Pusat Misi Pemeliharaan Perdamaian TNI (PMPP) di Kawasan IPSC Sentul, Kantor Pusat Kesehatan Mabes TNI di Cilangkap, Kantor Kesehatan Pelabuhan di Bandara Soekarno-Hatta, Cengkareng, dan pengiriman pertanyaan wawancara secara online kepada prajurit dan tenaga kesehatan Kontingen Garuda di Lebanon. Pengambilan sampel menggunakan teknik purposive sampling dengan mewawancarai pihak-pihak yang mengetahui, pernah bertugas, dan berkompeten terkait kondisi kesehatan di lapangan Kontingen Garuda di Lebanon, dan tenaga kesehatan di Kantor Kesehatan Pelabuhan Bandara Soekarno-Hatta untuk mengetahui kesiapan di tingkat nasional atas penyakit Leishmaniasis. Instrumen penelitian menggunakan pedoman wawancara untuk menggali informasi secara mendalam, dan rancangan penelitian bersifat crosssectional.

Penelitian ini juga menggunakan data sekunder yang diperoleh dari jurnal-jurnal internasional dan publikasi dari World Health Organization (WHO) di internet. Paper ini me-review 14 jurnal internasional dan satu publikasi yang berkaitan dengan simptom, perkembangan, pengobatan, dan cara pencegahan dan pengendalian infeksi Leishmaniasis untuk didapatnya pembahasan dan simpulan yang obyektif dan ilmiah.

Analisis paper ini menggunakan teknik Miles, Huberman dan Saldana ${ }^{10}$ yaitu data collecting (pengumpulan data), data condensation (kondensasi data), data display (menampilkan data), dan conclusion drawing (mengambil simpulan). Pengumpulan data dilakukan melalui wawancara mendalam dan review atas jurnal-jurnal internasional dan publikasi WHO yang terpilih. Kondensasi dan penampilan data dilakukan secara bersamaan dalam bentuk pemaparan di bagian 'Hasil dan Pembahasan' sedangkan pengambilan simpulan dilakukan di bagian 'Kesimpulan'. Pemilihan teknik Miles, Huberman dan
Saldana dianggap tepat agar dihasilkan pemaparan pembahasan yang singkat dan padat, mengingat banyaknya narasumber dan informan kunci yang diwawancarai, dan banyaknya jurnal yang harus direview untuk dilakukannya konfirmasi dan penentuan solusi/saran yang tepat demi didapatkannya hasil yang obyektif dan ilmiah.

\section{HASIL DAN PEMBAHASAN}

Paper ini menggunakan jurnal-jurnal dan publikasi dengan judul, penulis, penerbit, dan tahun terbit seperti pada table 1. Dari hasil wawancara mendalam, jurnal, dan publikasi tersebut, Penulis meringkasnya ke pembahasan sebagai berikut:

\section{Profil Gejala Penyakit Leishmaniasis dan Siklus Penularannya}

Sebelumnya dijelaskan bahwa gejala klinis Leishmaniasis terbagi menjadi 4, yaitu Cutaneous Leishmaniasis (CL), Mucocutaneous Leishmaniasis (ML), Visceral Leishmaniasis (VL), dan Post-KalaAzar-Dermal Leishmaniasis (PKDL) yang diakibatkan dari parasit intraselular dari genus Leishmania. Spesies dari parasit Leishmania adalah penentu apakah seseorang/inang akan mengalami CL atau VL. Permasalahan yang timbul ketika seseorang terinfeksi Leishmaniasis adalah parasit ini justru memperbanyak diri di dalam macrophages (sel darah putih) yang bertugas mewujudkan sistem imun tubuh. Tingkat keparahan Leishmaniasis sangat ditentukan oleh imunitas si penderitanya.

Parasit Leishmania pada CL menyerang kulit dan menimbulkan lesi (borok) yang dapat bersifat basah atau kering. Lesi yang basah lebih berisiko terkena infeksi sekunder akibat bakteri atau jamur. Lesi ini biasanya tidak terasa sakit, namun jika sudah terinfeksi bakteri atau jamur dapat menimbulkan rasa sakit. Lesi biasanya muncul di kulit tempat bekas gigitan lalat pasir dan dapat berpindah atau menyebar di sekitar bekas gigitan. CL biasanya dapat sembuh dengan sendirinya dalam beberapa bulan hingga 1 tahun. Namun jika tidak mendapat perawatan tambahan, bekasnya dapat sangat mengubah penampilan dan risiko infeksi sekunder akan lebih tinggi. Perempuan di Timur Tengah yang memiliki bekas lesi CL di wajah akan lebih sulit untuk menikah. Jika penyebab CL adalah dari spesies parasit Leishmania Tropica, ada risiko parasit dapat menimbulkan VL yang lebih berbahaya dan dapat mengancam nyawa. Cutaneous Leishmaniasis endemik di Benua Lama (Old World), utamanya di Eropa bagian selatan, Afrika Utara, Timur Tengah, Afganistan, dan Iran, maupun Benua Baru (New World), utamanya di Amerika Tengah dan Amerika Selatan. CL umumnya diakibatkan oleh infeksi parasit dari spesies Leishmania Tropica dan Leishmania Major di Benua Lama, dan Leishmania Braziliensis dan Leishmania Mexicana di Benua Baru. 
Tabel 1. Publikasi yang digunakan penulis

\begin{tabular}{|c|c|c|c|c|}
\hline No. & Judul & Penulis & Penerbit & $\begin{array}{l}\text { Tahun } \\
\text { Terbit }\end{array}$ \\
\hline 1. & $\begin{array}{l}\text { A Review of Preventative Methods } \\
\text { Against Human Leishmaniasis } \\
\text { Infection }\end{array}$ & $\begin{array}{l}\text { Lisa Stockdale dan } \\
\text { Robert Newton }\end{array}$ & $\begin{array}{l}\text { Plos Neglected Tropical } \\
\text { Diseases }\end{array}$ & 2013 \\
\hline 2. & Control of the Leishmaniasis & - & WHO & 2010 \\
\hline 3. & $\begin{array}{l}\text { Current Treatment of Leishmaniasis: } \\
\text { A Review }\end{array}$ & Lianet Monzote & $\begin{array}{l}\text { The Open Antimicrobial } \\
\text { Agents Journal }\end{array}$ & 2009 \\
\hline 4. & $\begin{array}{l}\text { Cutaneous Leishmaniasis and } \\
\text { Conflict in Syria }\end{array}$ & $\begin{array}{l}\text { Waleed S. Al- } \\
\text { Salem, dkk }\end{array}$ & $\begin{array}{l}\text { Center of Disease Control } \\
\text { and Prevention (CDC) }\end{array}$ & 2016 \\
\hline 5. & $\begin{array}{l}\text { Guideline for Diagnosis, Treatment } \\
\& \text { Prevention of Leishmaniasis in } \\
\text { Ethiopia }\end{array}$ & - & $\begin{array}{l}\text { Ethiopia Federal Ministry } \\
\text { of Health dan WHO }\end{array}$ & 2013 \\
\hline 6. & $\begin{array}{l}\text { Leishmania Tropica Infection in } \\
\text { Golden Jackals and Red Foxes, } \\
\text { Israel }\end{array}$ & $\begin{array}{l}\text { Dalit Talmi Frank, } \\
\text { dkk }\end{array}$ & $\mathrm{CDC}$ & 2010 \\
\hline 7. & $\begin{array}{l}\text { Leishmaniasis (Cutaneous and } \\
\text { Visceral) }\end{array}$ & - & $\begin{array}{l}\text { Center for Food Security } \\
\text { and Public Health Iowa } \\
\text { State University }\end{array}$ & 2017 \\
\hline 8. & Leishmaniasis in Syria & $\begin{array}{l}\text { Al-Nahhas S. dan } \\
\text { Altawil A. }\end{array}$ & $\begin{array}{l}\text { International Journal of } \\
\text { Cell Science \& Molecular } \\
\text { Biology }\end{array}$ & 2017 \\
\hline 9. & $\begin{array}{l}\text { Leishmaniasis: A Review on } \\
\text { Parasite, Vector, and Reservoir Host }\end{array}$ & $\begin{array}{l}\text { Bereket } \\
\text { Alemayehu dan } \\
\text { Mihiretu } \\
\text { Alemayehu }\end{array}$ & iMedPub Journals & 2017 \\
\hline 10. & $\begin{array}{l}\text { Revisiting Leishmaniasis in the } \\
\text { Time of War: the Syrian Conflict } \\
\text { and the Lebanese Outbreak }\end{array}$ & Ali Alawieh, dkk & $\begin{array}{l}\text { International Journal of } \\
\text { Infectious Diseases }\end{array}$ & 2014 \\
\hline 11. & $\begin{array}{l}\text { Sand Flies: Significance, } \\
\text { Surveillance, and Control in } \\
\text { Contigeency Operations }\end{array}$ & $\begin{array}{l}\text { Kenneth } \\
\text { Linthicum dan } \\
\text { Yvonne-Marie } \\
\text { Linton }\end{array}$ & $\begin{array}{l}\text { US Armed Force Pest } \\
\text { Management Board }\end{array}$ & 2015 \\
\hline 12. & $\begin{array}{l}\text { Vector and Reservoir Control for } \\
\text { Preventing Leishmaniasis }\end{array}$ & Gonzales U, dkk & $\begin{array}{ll}\text { The } & \text { Cochrane } \\
\text { Collaboration } & \end{array}$ & 2015 \\
\hline 13. & Vector Control in Leishmaniasis & K. Kishore, dkk & Indian J. Med Res 123 & 2006 \\
\hline 14. & $\begin{array}{l}\text { WHO Weekly Epidemiological } \\
\text { Record }\end{array}$ & - & WHO & 2017 \\
\hline 15. & $\begin{array}{l}\text { An Approach to Prevention of } \\
\text { Infectious Diseases during Military } \\
\text { Deployments }\end{array}$ & $\begin{array}{l}\text { Clinton K. Murray } \\
\text { dan Lynn L } \\
\text { Horvath }\end{array}$ & US Army Medical Center & 2007 \\
\hline
\end{tabular}

VL adalah bentuk Leishmaniasis yang paling berbahaya karena parasit menyerang organ dalam seperti hati, limpa, tulang sumsum, dan kelenjar getah bening. VL memiliki gejala seperti hepatosplenomegaly (pembesaran/pembengkakan hati dan/atau limpa), pancytopenia (berkurangnya sel-sel darah merah, putih, dan keping darah), anorexia/penurunan berat badan, demam tinggi, sakit di bagian perut, rasa lemas, penurunan imunitas tubuh, mual, dan diare. Masa inkubasinya antara 2 minggu hingga beberapa bulan atau tahun setelah parasit masuk ke dalam tubuh. VL dapat mengancam nyawa dan gejala penyakitnya seringkali sulit didiagnosa karena memiliki kemiripan dengan penyakit lain seperti misalnya malaria, tifus, demam berdarah, atau kanker darah. VL memiliki tingkat mortalitas tinggi dan tanpa perawatan yang segera, penderita VL dapat terancam nyawanya. Jika seseorang dari daerah non-endemik masuk ke daerah endemik dan terinfeksi VL, ada risiko tinggi terjadinya kasus haemolytic anaemia akut, kerusakan renal (ginjal) akut, dan pendarahan mukosal. VL utamanya endemik di Sub-Benua India, Afrika Timur, dan Amerika Selatan. VL biasanya diakibatkan oleh infeksi parasit dari spesies Leishmania Donovani, dan Leishmania Infantum di Benua Lama, dan Leishmania Infantum/Chagasi di Benua Baru.

ML adalah kondisi dimana CL terjadi di jaringan mukosal (jaringan lunak di hidung dan mulut). Di kondisi yang parah, penderitanya dapat mengalami 
kerusakan di bagian hidung, laring, dan faring, bahkan kematian akibat tercekiknya saluran pernafasan dan makanan yang ditimbulkan dari pembengkakan. ML dapat muncul jika seseorang yang menderita CL tidak mendapat pengobatan setelah beberapa tahun (utamanya di Benua Baru).

Lesi ML di bagian laring yang sudah kronis dapat menimbulkan kesalahan diagnosa penyakit kanker. Kasus ML tergolong lebih jarang dibandingkan CL ataupun VL, namun kasus ML muncul lebih sering di negara-negara Benua Baru seperti Peru, Bolivia, dan Brazil, walaupun di Benua Lama juga dapat terjadi, seperti misalnya di India atau Sudan. Perlu menjadi catatan penderita CL atau VL yang mengalami penurunan sistem imun tubuh (immunosuppression), atau yang mengalami PKDL juga dapat terjangkit ML. Di Benua Baru, spesies Leishmania penyebab ML yang utama adalah Leishmania Braziliensis dan Leishmania Panamensis sedangkan di Benua Lama penyebabnya adalah Leishmania Infantum, Leishmania Mayor, dan Leishmania Tropica.

Post-Kala-Azar-Dermal Leishmaniasis adalah komplikasi yang muncul setelah seseorang sembuh dari VL, yaitu ketika parasit VL menyerang kulit (Cutaneous) yang ditandai dengan munculnya bintilbintil atau bercak di kulit yang umumnya berada di bagian wajah dan sekitar kemaluan. Biasanya kemunculan PKDL adalah akibat teknik pengobatan Leishmaniasis yang tidak sempurna atau sistem imunitas penderita yang menurun. Perlu menjadi catatan bahwa penderita PKDL dapat menjadi inang dari penyebaran VL dan negara yang umum mengalaminya adalah India, Bangladesh, dan Sudan/Afrika Timur. ${ }^{11}$ Umumnya PKDL diakibatkan oleh parasit Leishmania Donovani, namun kasus yang diakibatkan oleh Leishmania Infantum dan Chagasi juga pernah terjadi. ${ }^{12}$ Di Afrika Timur, pasien PKDL dapat sembuh dengan sendirinya, namun hal ini sangat jarang terjadi di India.

Siklus penularan Leishmaniasis pada manusia dapat dilihat pada Gambar 1:

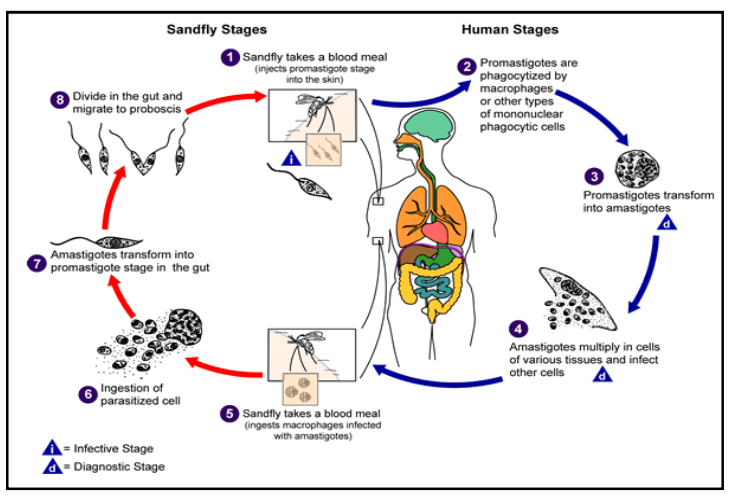

Gambar 1. Siklus Perkembangan Protozoa Leishmania Pada Manusia (cdc.gov)

\section{Vektor Penyakit Leishmaniasis}

Infeksi Leishmaniasis disebarkan oleh vektor lalat pasir betina (Phlebotomus di benua lama dan Lutzomyia di benua baru) yang di dalam tubuhnya sudah terdapat parasit Leishmania. Lalat pasir umumnya berhabitat di tempat yang kering, lembab, dan mengandung banyak zat organik. Lalat pasir tidak seperti nyamuk yang membutuhkan genangan air untuk bereproduksi dan justru tidak ada jika cuaca terlalu basah atau terlalu dingin. Lalat pasir menyukai tempat yang terlindungi dan lembab (tidak terlalu basah) seperti misalnya di rekahan tembok, sarang rayap, di balik batu, kulit pohon, sarang tikus, dan sarang rubah. Lalat pasir membutuhkan darah untuk perkembangan telur-telurnya seperti halnya nyamuk Anopheles dan Aedes Aegypti. Ukuran lalat pasir sangat kecil yaitu sekitar 1,5 mm (lebih kecil dari nyamuk) dan suaranya saat terbang dapat tidak terdengar sama sekali karena memiliki banyak bulu. Ukuran yang lebih kecil dari nyamuk memungkinkannya dapat lolos dari kelambu tidur anti-nyamuk. Lalat pasir bukan penerbang yang baik, namun pernah tercatat dapat terbang hingga sejauh $2 \mathrm{~km}$, dan perpindahannya sangat mungkin didukung oleh angin. Spesies lalat pasir tertentu dapat bersifat oportunis dalam mencari mangsa untuk dihisap darahnya, apakah dari hewan ataupun manusia sehingga siklus infeksi Leishmaniasis dapat bersifat zoonosis maupun antroponosis.

Kemampuan adaptasi lalat pasir juga cukup baik karena dapat hidup di daerah urban dan rural dan dapat hidup di dalam rumah (endophilic) maupun luar rumah (exophilic). Siklus zoonosis biasanya melibatkan hewan inang seperti anjing, rubah merah, tikus, hyrax, kelinci telinga panjang (hare), serigala, dan lain sebagainya. Siklus Leishmaniasis yang bersifat zoonosis dan antroponosis membuat pemberantasannya sangat sulit, terlebih lalat pasir itu sendiri memiliki kemampuan adaptasi yang tinggi akibat perubahan iklim, dan semakin resisten dengan obat pembunuh serangga (DDT). ${ }^{13}$

Kontingen Garuda di Lebanon sangat berisiko terinfeksi CL pada tingkatan yang tinggi dan VL pada tingkatan yang sedang. Hal ini karena tingginya kemungkinan berjalannya siklus CL yang bersifat antroponosis, utamanya di tempat-tempat pengungsian dan sekitarnya akibat cukup tingginya jumlah pengungsi asal Suriah yang sudah terinfeksi. Para pengungsi ini sebagian besar terinfeksi CL yang diakibatkan spesies Leishmania Tropica dan Leishmania Major. Namun ada juga risiko infeksi VL mengingat pernah adanya kasus pengungsi asal Suriah yang menderita VL akibat infeksi dari parasit Leishmania Infantum.

Penderita VL di antara pengungsi Lebanon memang tidak tinggi, namun dengan proporsi infeksi Leishmania Tropica yang tinggi di antara para pengungsi, memungkinkan adanya kasus CL yang mengalami visceralization (kasus dimana CL berubah menjadi VL di tubuh penderita). Mengingat Leishmaniasis bukan penyakit endemik di Indonesia, 
menandakan imunitas masyarakat Indonesia pada umumnya terhadap penyakit ini rendah. Artinya jika risiko infeksi CL yang diakibatkan Leishmania Tropica cukup tinggi di Lebanon, ada kemungkinan sangat tinggi parasit ini akan mengalami visceralization jika berhasil masuk ke tubuh prajurit Kontingen Garuda. Kabar buruknya lagi adalah adanya tendensi terjadinya visceralization dari infeksi parasit Leishmania Major. ${ }^{14}$ Tidak menutup kemungkinan juga dapat terjadi kasus ML setelah prajurit terinfeksi CL di Lebanon akibat imunitas prajurit Kontingen Garuda yang memang masih belum diketahui resistensinya terhadap infeksi Leishmaniasis. Artinya persoalan Leishmaniasis di Lebanon adalah masalah yang serius dan harus mendapat perhatian yang lebih. Wilayah di Lembah Bekaa adalah hotspot kasus CL di Lebanon yang harus diwaspadai Kontingen Garuda. Hal ini karena Lembah Bekaa merupakan salah satu titik pengungsian (asal Suriah) yang besar dan iklimnya sangat cocok untuk perkembangan lalat pasir.

\section{Pengobatan Leishmaniasis}

Hingga saat ini belum ditemukan vaksin maupun chemoprophylaxis untuk Leishmaniasis. Obat-obatan perawatan Leishmaniasis sudah ada, seperti Antimonial Pentavalent, Pentamidine, Miltefosine, Paromomycin, dan Liposomal Amphotericin B, namun obat-obatan tersebut memiliki tingkat toksisitas yang tinggi. Miltefosine, Paromomycin, dan Liposomal Amphotericin $B$ dianggap lebih aman dan sudah mendapatkan izin dari Badan Pangan dan Obat-Obatan Amerika Serikat (Food and Drug Administration) untuk perawatan Leishmaniasis. Orang yang mengonsumsi obat-obatan tersebut dapat mengalami efek samping seperti rasa mual, diare bahkan anorexia, dan tidak boleh dikonsumsi orang yang sedang hamil atau menyusui. Tingginya toksisitas juga menjadikan obat-obatan ini dapat mengakibatkan kematian. Harga obat-obatan ini juga tergolong mahal dan pengobatan oral yang saat ini yang dianggap paling efektif dan aman adalah Miltefosine. Namun, di beberapa kondisi, parasit Leishmania mulai memiliki resistensi atas obat-obatan yang paling efektif sekalipun seperti Liposomal Amphotericin B, Paromomycin, dan Miltefosine yang terbukti dari adanya kasus relapse atau kekambuhannya kembali setelah sembuh menggunakan obat-obatan tersebut. $^{15}$ Penggunaan obat-obatan yang tidak sesuai dengan resep ahli kesehatan, penghentian proses pengobatan secara sepihak oleh pasien/penderita(akibat tidak tahan dengan dampak toksisitas yang tinggi atau merasa sudah baikan sehingga merasa tidak perlu meminum obat lagi), dan co-infeksi pasien penderita Leishmaniasis dengan penyakit HIV membuat Leishmaniasis semakin sulit disembuhkan.

Pengobatan Leishmaniasis, khususnya yang menggunakan miltefosine dapat memakan waktu hingga satu bulan sehingga jika seorang prajurit terinfeksi, cukup dapat mengganggu kemampuannya menjalankan operasi. Efek sampingnya juga dapat mengganggu aktivitas bahkan membahayakan kesehatan dan keselamatan (dapat menimbulkan dehidrasi akibat mual dan diare). Pengobatan biasanya juga harus bersamaan didukung dengan bantuan nutrisi tambahan dan vitamin untuk hasil yang maksimal. Berdasarkan kondisi ini, cara terbaik agar aman dari infeksi Leishmaniasis adalah mencegah jangan sampai digigit lalat pasir.

\section{Teknik Pencegahan dan Pengedalian Leishmaniasis}

Mengingat Leishmaniasis merupakan penyakit yang cukup sulit disembuhkan dan belum ada vaksinnya, cara terbaik untuk menghindarinya adalah dengan menghindari gigitan lalat pasir betina. Memutus daur hidup parasit Leishmania juga sangat penting untuk membatasi risiko terjadinya epidemi, yang intinya adalah dengan mengontrol infeksinya di inang hewan dan manusia, serta pemberantasan dan "pembatasan" vektor. Dalam mencegah dan mengendalikan infeksi Leishmaniasis, beberapa hal yang dapat dilakukan adalah sebagai berikut:

1. Memakai alat pelindung diri. Krim penangkal gigitan serangga dan penggunaan pestisida di pakaian dan kelambu tidur dapat mengurangi risiko gigitan lalat pasir secara efektif.

2. Menjaga kebersihan lingkungan dari tumpukan sampah. Sampah merupakan unsur organik yang disukai lalat pasir, dan juga tikus, anjing, dan rubah, inang hewan dari parasit Leishmania. Dengan menjaga kebersihan lingkungan, menjauhkan sampah dari tempat tinggal penduduk dan memusnahkannya, risiko infeksi Leishmaniasis dapat ditekan.

3. Melakukan pemberantasan vektor dan inang hewan. Pemberantasan lalat pasir dapat dilakukan dengan penyemprotan pestisida, menggunakan umpan beracun, atau ditangkap menggunakan alat penangkap serangga seperti sinar yang menarik bagi serangga. Pemberantasan inang hewan seperti tikus, anjing, rubah, dan lain sebagainya juga harus dilakukan khususnya di dekat tempat tinggal penduduk. Hewan-hewan ini menjaga siklus parasit Leishmania secara zoonosis sehingga manusia yang ada di sekitarnya berisiko terinfeksi Leishmaniasis.

4. Mengisolasi pasien Leishmaniasis dari gigitan lalat pasir dan mengobatinya. Penderita Leishmaniasis adalah inang yang dapat menjadi medium berkembangnya amastigot parasit Leishmania untuk kemudian terhisap kembali oleh lalat pasir yang tidak terinfeksi, dan kemudian lalat pasir ini menginfeksi kembali parasit Leishmania kepada orang lain yang digigitnya. Jika untuk sementara waktu penderita diisolasi dan diobati hingga sembuh, risiko berputarnya kembali siklus parasit Leishmania dapat dikurangi.

5. Memberikan pendidikan kepada masyarakat mengenai siklus hidup penyakit Leishmaniasis 
dan teknik pencegahannya. Pemerintah dan tenaga kesehatan harus aktif menjalankan program pengendalian inang dan vektor dengan melibatkan partisipasi aktif masyarakat sehingga program ini dapat dijalankan secara mandiri dan berkelanjutan namun tetap dapat dipertanggungjawabkan.

6. Merekayasa lingkungan sekitar tempat tinggal agar tidak cocok bagi habitat lalat pasir. Lalat pasir hidup di tempat yang kering namun lembab dan terdapat banyak zat organik. Berdasarkan hal ini, lingkungan di sekitar rumah dapat dibuat hanya sedikit menyimpan kelembaban dengan memastikan tidak adanya genangan air dan cekungan, membeton atau mengaspal tanah, dan menanam tanaman penangkal serangga, khususnya yang dapat menolak lalat pasir seperti lavender atau menyebarkan kulit jeruk.

7. Membuat tempat tinggal yang "kedap" lalat pasir dan tikus. Tempat tinggal tidak boleh memiliki celah yang dapat dimasuki lalat pasir atau cocok untuk menjadi tempat tinggal lalat pasir, misalnya dengan membiarkan adanya retakan di tembok. Tikus juga menjadi sumber makananan dan sarangnya dapat menjadi tempat yang "menguntungkan" bagi lalat pasir sehingga menjamin tidak adanya sarang tikus di dalam dan sekitar rumah adalah wajib untuk menghindari siklus zoonosis di sekitar tempat tinggal.

8. Mengurangi aktivitas di luar rumah sejak matahari terbenam hingga terbit. Lalat pasir adalah hewan nokturnal (aktif di malam hari) sehingga pengurangan aktivitas di malam hari dapat menurunkan risiko digigit lalat pasir.

9. Waspada atas peningkatan populasi lalat pasir saat menjelang musim dingin (di iklim subtropis). Terdapat korelasi antara periode menjelang musim dingin dengan peningkatan kasus infeksi Leishmaniasis. Artinya di periode ini program pemberantasan vektor harus diutamakan dan penggunaan alat pelindung diri wajib dilakukan.

10. Menggratiskan obat dan konsultasi kesehatan terkait penyembuhan Leishmaniasis. Obat Leishmaniasis yang efektif masih relatif mahal dan penggunaannya secara sembarangan menimbulkan parasit yang resisten terhadap obat. Dengan penggaratisan obat sekaligus konsultasinya, penderita Leishmaniasis dapat disembuhkan dan yang terpenting tidak lagi menjadi inang yang dapat menjaga siklus hidup parasit secara antroponosis.

\section{Strategi Memperkecil Risiko Infeksi atas Prajurit Kontingen Garuda di Lebanon}

Langkah-langkah untuk memperkecil risiko infeksi atas prajurit Kontingen Garuda di Lebanon tidak terlalu berbeda dengan penjelasan di bagian sebelumnya. Secara spesifik, Kontingen Garuda harus melaksanakan langkah sebagai berikut:

1. Mendapat dukungan dari pusat (Mabes TNI) dalam bentuk kebijakan untuk pencegahan dan pengendalian Leishmaniasis. Peraturan Panglima TNI terkait kesehatan prajurit harus melingkupi penanganan penyakit Leishmaniasis. Hal ini sangat krusial agar terdapat payung hukum yang kuat sehingga upaya penanganan Leishmaniasis dapat dilakukan secara efektif.

2. Menjalankan pendidikan mengenai penyakit Leishmaniasis kepada para prajurit, baik kombatan maupun non-kombatan, serta tenaga kesehatan TNI yang akan bertugas di Lebanon. Kewaspadaan atas infeksi Leishmaniasis harus ditumbuhkan sedini mungkin kepada prajurit TNI yang akan melaksanakan misi luar negeri yang endemik Leishmaniasis. Tenaga kesehatan TNI juga harus dipastikan memiliki keahlian untuk mendiagnosa/mendeteksi, dan mengobati prajurit yang terinfeksi Leishmaniasis.

3. Menyediakan mekanisme perlindungan prajurit dari gigitan lalat pasir. Pakaian dan kelambu tidur prajurit harus diberikan permethrin dan setiap prajurit harus diberikan krim DEET untuk menolak gigitan serangga, baik saat prajurit beristirahat maupun melaksanakan misi. Bagi yang bertugas di malam hari, penggunaan krim DEET dan seragam ber-permethrin adalah wajib untuk mengurangi risiko gigitan lalat pasir.

4. Menjalankan program pemberantasan vektor dan inang. Penyemprotan pestisida di sekitar kompon/barak harus dilakukan secara terjadwal, misalnya sebulan sekali atau ketika terjadi lonjakan populasi serangga di waktu tertentu (misalnya menjelang musim dingin). Pemberantasan inang seperti pembongkaran dan pembasmian sarang dan populasi tikus, anjing liar, dan rubah di sekitar kompon juga harus dilakukan.

5. Mencadangkan obat untuk perawatan infeksi Leishmaniasis dan obat-obatan pengurang simptom yang timbul dari infeksi Leishmaniasis seperti obat anti-mual, diare, demam, dan antibiotik untuk kulit. Suplemen nutrisi dan vitamin juga harus disiapkan untuk proses pengobatan yang lebih efektif.

6. Melakukan rekayasa lingkungan. Sebagian besar tanah di kompon sebaiknya harus tertutup beton atau aspal untuk menjauhkan sarang tikus dan mencegah lalat pasir dapat mengakses tanah di dalam kompon.

7. Menjaga kebersihan lingkungan. Kebersihan di kompon harus selalu dijaga agar tidak terdapat tumpukan sampah agar tidak mengundang lalat pasir, anjing liar, tikus, dan rubah.

8. Menjaga kualitas gizi para prajurit. Gizi yang baik menjamin imunitas yang baik pula sehingga risiko berkembang bebasnya parasit di dalam tubuh dapat ditekan.

Perlu diketahui bahwa penyakit Leishmaniasis belum menjadi topik yang mendapat perhatian "lebih" dari pemerintah Indonesia. Padahal dengan semakin tingginya mobilitas masyarakat Indonesia ke negaranegara endemik Leishmaniasis dan pemanasan global, membuat penyakit ini berisiko tinggi menginfeksi 
masyarakat. Hingga saat ini, belum pernah ada kasus prajurit Kontingen Garuda yang terinfeksi Leishmaniasis. Penyemprotan serangga, penggunaan krim DEET dan kelambu tidur, dan menjaga kebersihan lingkungan dilakukan secara rutin oleh Kontingen Garuda, namun sebenarnya Leishmaniasis belum masuk ke dalam Peraturan Panglima TNI sebagai penyakit yang harus diperhatikan. Pemerintah Lebanon juga rajin melakukan pengendalian vektor Leishmaniasis sehingga mungkin hal ini turut berpengaruh pada belum adanya kasus infeksi Leishmaniasis atas prajurit di Lebanon. Artinya TNI dan Pemerintah Indonesia harus memberikan perhatian lebih besar atas penyakit Leishmaniasis. Ketika pemerintah Lebanon tidak lagi mampu melaksanakan program pengendalian infeksi Leishmaniasis (mengingat Lebanon sedang di ambang krisis), tentu prajurit Kontingen Garuda akan semakin berisiko untuk terinfeksi, selain sudah banyaknya imported case Leishmaniasis di Lebanon dari pengungsi Suriah.

\section{SIMPULAN}

Kedatangan pengungsi Suriah di Lebanon meningkatkan risiko infeksi penyakit Leishmaniasis atas prajurit Kontingen Garuda. Infeksi Leishmaniasis dapat mengancam kesehatan prajurit sehingga mengganggu kelancaran pelaksanaan misi perdamaian. Belum adanya vaksin dan toksisitas obat yang masih cukup tinggi menuntut prajurit untuk melakukan cara terbaik menghindari infeksi Leishmaniasis. Kuncinya adalah dengan menggunakan alat pelindung diri, melakukan pemberantasan vektor dan inang, menjaga kebersihan lingkungan, menjalankan rekayasa lingkungan, dan mencadangkan obat-obatan. Agar pelaksanaannya efektif, TNI melalui Peraturan Panglima perlu memasukkan Leishmaniasis sebagai penyakit yang harus diwaspadai. Hal ini agar terdapat sinergi antara kebijakan di komando pusat dengan pelaksana di lapangan demi menjaga kesehatan prajurit Kontingen Garuda dari ancaman infeksi Leishmaniasis.

\section{DAFTAR PUSTAKA}

1. World Health Organization. Control of the Leishmaniasis. Geneva: WHO; 2010.

2. World Health Organization. Weekly Epidemiological Record 2017, 92(38): 557 - 572

3. Al-Salem W, Pigott DM, Subramaniam K, Haines LR, Kelly-Hope L, Molyneux DH, et al. Cutaneous Leishmaniasis and conflict in Syria. Emerg Infect Dis 2016, 22(5): 931-933.

4. UNHCR. Registered Syrian Refugee in Lebanon [Internet]. Situation Syria Regional Refugee Response. 2018 [diakses 01 Februari 2019]. Tersedia melalui: https://data2.unhcr.org/en/ situations/syria/location/71

5. Associated Press. UN: Ceasefire violations may spark Lebanon-Israel conflict [Internet]. Ynetnews. News; 2018 [diakses pada 02 Januari 2019]. Tersedia melalui: https://
www.ynetnews.com/articles/0,7340,L5338491,00.html

6. Koch LK, Kochmann J, Klimpel S, Cunze S. Modeling the climatic suitability of Leishmaniasis vector species in Europe. Scientific Reports 2017, 7(1): $1-10$

7. Alawieh A, Musharrafieh U, Jaber A, Berry A, Ghosn N, Bizri AR. Revisiting Leishmaniasis in the time of war: the Syrian conflict and the Lebanese outbreak. International Journal of Infectious Diseases 2014, 29:115-9.

8. Magill AJ, Grogl M, Gasser RA, Sun W, Oster $\mathrm{CN}$. Visceral infection caused by Leishmania tropica in veterans of Operation Desert Storm. New England Journal of Medicine 1993, 328(19):1383-7.

9. Hajj RE, Hajj HE, Khalifeh I. Fatal Visceral Leishmaniasis Caused by Leishmania infantum, Lebanon. Emerging Infectious Diseases 2018, 24(5):906-7.

10. Miles MB, Huberman AM, Saldaña Johnny. Qualitative data analysis: a methods sourcebook. Los Angeles: SAGE; 2014.

11. Zijlstra, E., Musa, A., Khalil, E., El Hassan, I., \& El-Hassan, A. Post-kala-azar dermal Leishmaniasis. The Lancet Infectious Diseases 2003, 3(2), 87-98.

12. Das NK, Datta PK, Mukhopadhyay D, Chatterjee M. Post Kala-Azar Dermal Leishmaniasis: An Update. dalam buku Recent Advances in Dermatology. 1st ed. New Delhi: Jaypee Brothers Ltd.; 2013: 154-75.

13. Dhiman RC, Yadav RS. Insecticide resistance in phlebotomine sandflies in Southeast Asia with emphasis on the Indian subcontinent. Infectious Diseases of Poverty 2016, 5(1):1-10

14. MF Soliman. The Persistence, Dissemination, and Visceralization Tendency of Leishmania Major in Syrian Hamsters. Acta Tropica 2006, 97(2): 146150.

15. Lagadinou M, Dimitropoulou D, Assimakopoulos SF, Davoulos G, Marangos M. Recurrent visceral Leishmaniasis in an immunocompetent patient: a case report. Journal of Medical Case Reports 2013, $7(1): 1-4$ 